\title{
OBSERVATIONS ON THE BALL-ROLLING BEHAVIOR OF CANTHON PILULARIUS (L.) (COLEOPTERA, SCARABAEIDAE)
}

\author{
By Eric G. Matthews ${ }^{1}$ \\ Department of Biology, University of Puerto Rico, Río Piedras
}

The present paper describes some aspects of the normal behavior of Canthon pilularius (L.) (C. laevis [Drury]) in the field and is the result of direct observations totalling about 57 hours, carried out in four field locations in Florida and Georgia in 1957 and I96r.

The approach of this study is neither ethological nor ecological, but taxonomic. That is to say, certain aspects of the normal behavior of the scarab were investigated and quantified with a view to using them as taxonomic characters in comparison with other related species and genera. My data on other species of the genus Canthon are not yet complete enough to present an interspecific analysis of the behavior of this genus, but are adequate for an intergeneric comparison with European representatives of the ball-rolling genera Scarabaeus, Gymnopleurus, and Sisyphus, which have been studied in detail by German investigators. Such a comparison is now in preparation by the author and will be published subsequently.

Previous literature gives the outlines of the life history of $C$. pilularius (Lindquist, I935; Cooper, 1938; Ritcher, 1945; Miller, 1954), but there are no published observations describing the behavior sequences seen. Brief notes on the biology of about 25 other species of Canthon, sensu stricto, have been recorded in the literature (see von Lengerken, 1954, Pereira and Martínez, 1956, and Halffter, I959, for discussions).

This species is commonly known in the United States literature as Canthon laevis (Drury). However, it has been known for some time that this is not the correct name. In a recent revision of the genus (Halffter, I96I) there is a review of the reasons showing why the name pilularius Linnaeus, I 758 , is most probably correctly attributed to this species. Furthermore, Lane (1950) shows that even the name hudsonias Forster, I77I, has precedence over laevis Drury, I 773.

\footnotetext{
${ }^{1}$ The present investigation was supported in part by Postdoctoral Research Fellowship No. 12,061 of the National Institute of Mental Health, N.I.H., U. S. Public Health Service, while the author was at the Biological Laboratories, Harvard University. Publication of this work was aided by a grant from The Society of the Sigma Xi and RESA Research Fund.

Manuscript received by the editor September 12, 1962.
} 


\section{Acknowledgments}

I wish to acknowledge the helpfulness shown by the University of Florida in general and Mr. William M. Dunson in particular in extending to me the facilities of the Welaka Reserve, on which some of this study was carried out. Mr. O. L. Cartwright of the United States National Museum made the authoritative determinations identifying the specimens involved. To Dr. Howard E. Evans of the Museum of Comparative Zoology and Dr. F. M. Carpenter of the Biological Laboratories, Harvard University, I am particularly grateful for reading the manuscript and making many helpful suggestions.

\section{Methods}

The methods used consisted of sitting down and watching the activities of the scarabs after a quantity of human faeces or cow dung had been placed in a suitable location. Complete notes were taken describing the actions of the beetles involved, the rolling patterns were diagrammed in the field notebook, and pertinent data such as time in minutes, distances rolled (measured with a metric tape measure), terrain features, wind direction, sun position, etc. were recorded. The author always camped in the immediate area of observation so that he could be present for every phase of activity from beginning to end. Often several days were spent in the same spot, and it need hardly be mentioned that every hour of observation represents many additional hours of waiting. No special techniques were used and no experimentation was attempted. Beetles were marked with dabs of clear nail polish mixed with oil paints in different color combinations for identification; these markings were found not to last for more than a day or so because of the burrowing activity of the beetles.

The study was carried out near Arcadia, De Soto County, Florida, on 27 March, 1957, in the Osceola National Forest, Columbia County, Florida, on 7 - I I June, 1957, near Brunswick, Glynn County, Georgia, on 13 - I4 June, I957, and near Welaka, Putnam County, Florida, on 24 April - 6 May, 196r.

The illustrations (figs. I - 5) are traced exactly from photographs taken by the author and may be considered completely accurate in regard to the positions and the attitudes of the beetles and the general size and shape of the balls.

\section{Distribution and Color Phases}

Canthon pilularius (L.) is widespread in the eastern half of the United States from extreme south-eastern Wyoming, Kansas, Oklahoma, and northern Texas eastward. It is replaced in most of Texas 
and the Southwest by the closely related $C$. imitator Brown, which also occurs in Oklahoma, Arkansas, Louisiana, and Florida. In northern Florida east of the Apalachicola River and in southern Georgia a green or bronze phase of pilularius largely replaces the usual black one, while in most of peninsular Florida the species is largely represented by a blue-black phase which becomes intensely blue in the Keys. A more extensive discussion of the color phases will be found in Halffter ( I96I). The present observations are on all three color phases - green or bronze, black, and blue-black - and several instances of sexual pairing between all possible color combinations were observed, supporting the taxonomic evidence that there are no specific differences between them.

\section{Morphology}

The beetles are large ( IO - I9 mm in length), broadly oval, and somewhat flattened (figs. I - 5). The head and legs are used extensively in the behavior described below and should therefore be briefly described. The head is strongly flattened and broad, with sharp edges, and is an excellent digging tool. The fore tibiae are strongly flattened and provided with teeth on the outer edges. The forelegs are used extensively in cutting and manipulating the dung and in patting the surface of the dung ball, as well as in digging. The middle and hind tibiae are very slender and a little curved and are used in rolling and guiding the dung ball. For a very detailed study of the morphology of the genus, see Halffter (196i).

The mouthparts have been described by several authors (Hardenberg, I907; Mohr, I930; Pereira and Martínez, i956; Miller, I96r) and do not concern us here, particularly. The latter author showed that the molar surfaces of the mandibles are so constructed as to be capable of a very thorough grinding action. Beetles with a mandible removed were unable to feed.

There is no sexual dimorphism, other than in the forespur, and it is therefore not possible to determine the sex of a beetle without examining it closely. This complicates observation somewhat and means that a behavior sequence must be interrupted or allowed to be completed before the sex of the participants can be determined. This can be done by looking at the forespur (a lens is usually not necessary), which is bifurcate in the male and simply acute in the female.

\section{Ecology}

The autecology of this species has not been properly investigated (nor has that of any other American coprophage). It is common 
knowledge that the species feeds on cow dung in pastures, and my observations indicate that older dung is preferred. Decaying meat rarely attracts the beetles (Lindquist, I935) and cadavers of small vertebrates may occasionally be made into balls and rolled off (Bragg, $1957^{2}$ ), as is commonly seen in some South American species of the genus (Luederwaldt, I9II). Human dung is readily taken, and many of the observations which follow are based on feeding behavior with human faeces.

Miller (1954) analysed the role of I7 species of coprophagous scarabs in the dispersal of human faeces in the same general geographical area in which this study was carried out. He found that C. pilularius made up $64 \%$ of the scarabs collected at human fecal traps in an open field in the daytime and that this species, because of its size, is potentially capable of removing more than $90 \%$ of the total exposed human dung removed by scarabs in the daytime, or $61 \%$ of the total at all times. This makes it by far the most important species of coprophage in this ecological situation (open fields). Tumble-bugs (Canthon, sensu lato) are not important in heavily overgrown situations, indicating the importance of the surrounding terrain.

The recent very fine studies of Landin (196I) on the ecology of Aphodiinae finally prove for this group what has long been suspected by students of the coprophages in general, namely, that it generally makes no difference what kind of dung is eaten by a given species, but only where it is deposited, that is, to what extent it will be affected by heat and desiccation. If the type of dung is important (as for instance in the cases of cow and horse dung), it is because its consistency or shape may influence temperature changes and evaporation rates (Landin, op. cit.).

In $C$. pilularius activity is at the highest level in the spring and is very much dependent on rains, the most intense activity being seen immediately after showers. Activity usually begins at about o9oo on warm days (when the shade temperature reaches about $90^{\circ} \mathrm{F}$ by I IOO) and terminates at about I 700 . During dry spells the beetles remain continuously inside cow droppings under the crust and I have not seen them spending this time in the soil. No studies have been made regarding optimal temperature and humidity limits for this species.

In the localities in which I observed this species the soil consisted

\footnotetext{
${ }^{2}$ Bragg's observations on the rolling of decaying tadpoles were apparently made in central Oklahoma and therefore perhaps on the closely related Canthon imitator Brown.
} 
entirely of white sand and was largely exposed, either on sand roads or open pastures.

\section{Ball-rolling Behavior}

The apparent function of the making and rolling of a ball of dung is to transport the dung away from the dropping and bury it to be eaten underground, where it is protected from desiccation. The dung ball serves as food either for the beetle rolling it or for the future larva. Reproductive activity is seen almost entirely during the spring months (March - May), after which adult feeding activity predominates. The behavior sequence in relation to the ball is significantly different depending on whether the dung ball is to serve as adult or larval food.

In the following account, the making and rolling of the food ball will be dealt with first. Quantitative or important statements are followed by a number in parentheses; this indicates the number of observations upon which the previous statement is based. This is to enable the reader to judge the relative reliability of a statement. Apparent discrepancies in these observation numbers are due to the fact that many fragmentary sequences were observed. Anthropomorphisms must be excused by the reader in the interest of avoiding lengthy circumlocutions.

\section{The Food Ball}

With regard to the food ball, both sexes behave the same way, acting individually. The sequence involved in the making, rolling, and burial of the ball is as follows: I) Approaching the dung source, 2) cutting, 3) shaping, 4) rolling, and 5) burial of the ball. An additional section below is devoted to underground feeding.

The approach. When there is a wind, the beetles will approach a source of dung from down-wind, flying very low in zig-zags. At a certain moment, perhaps when the odor currents are encountered at a certain frequency, the beetle suddenly "cuts" its power and drops like a stone to the ground, often landing on its back. The point where it lands may be from three to $80 \mathrm{~cm}$ from the dung, usually $10-15 \mathrm{~cm}(5)$. The beetle then approaches on foot, moving jerkily with antennae outstretched. One beetle was seen to approach entirely on foot and was first spotted $150 \mathrm{~cm}$ away. The time it took for individual beetles to locate a given source of (human) dung after deposition varied from less than one minute to five hours and 30 min (23). Conversely, a given source of dung took from less than one minute to one hour and ten minutes to be first discovered by this species, the average being $23 \mathrm{~min}(6)$. Of course, these figures 


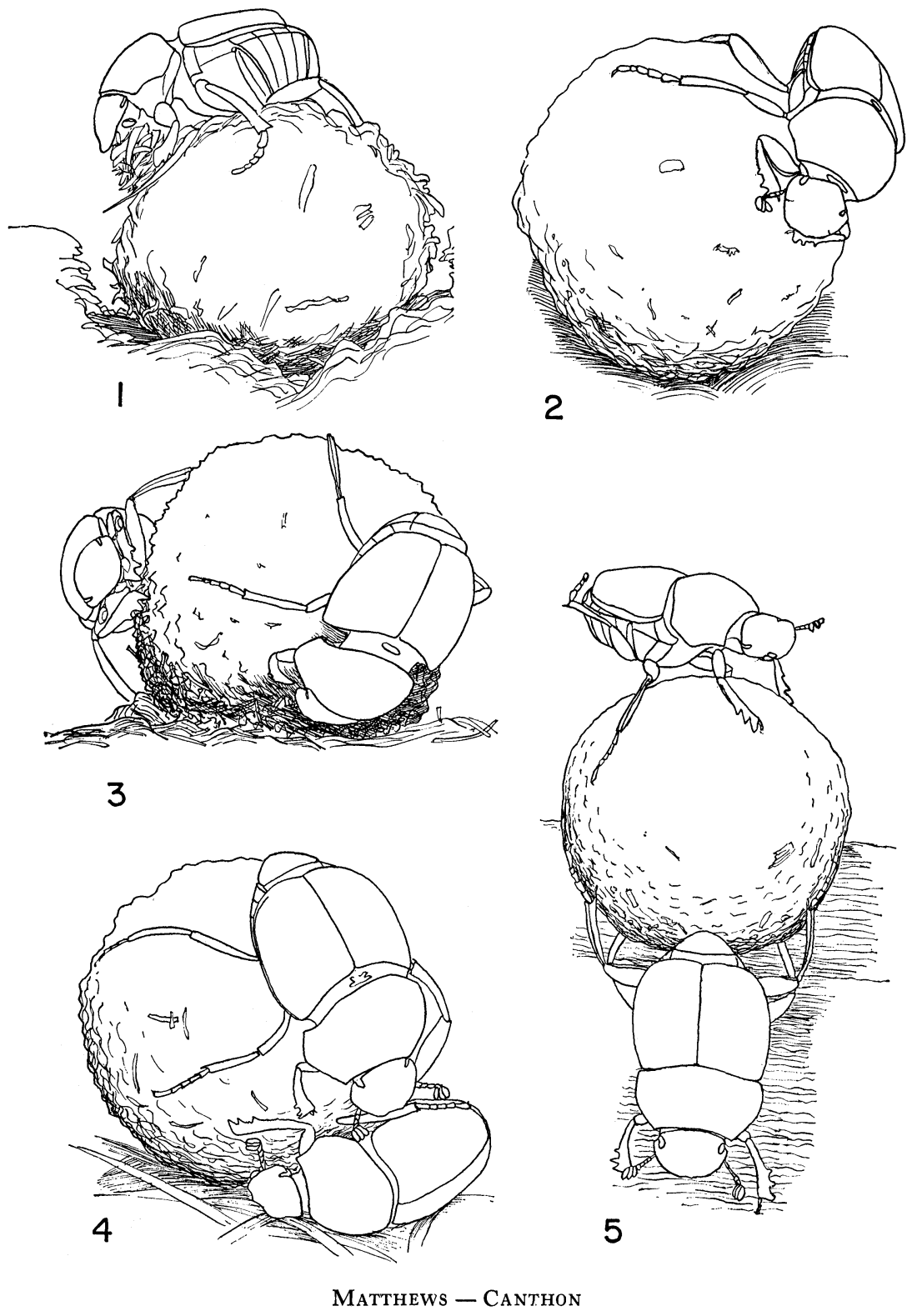


depend a great deal on very variable factors such as the density and searching activity of the beetles and the amount of dung in a given area.

Cutting. Once a beetle has come up to a source of dung it begins immediately to start cutting a ball from the nearest portion. This process involves climbing on the dung and cutting a circular groove with the head and forelegs, the beetle pivoting in a circle. The dung is bunched up under the beetle with the forelegs and quickly acquires a ball-like shape (fig. I). When the bunched dung is of a certain quantity, it is detached by reaching under and cutting the lump away at the base in a circle (fig. 3 ). At this point, if the quantity of dung in the lump is adequate, shaping begins. If it is not, the beetle, resting on the lump, reaches out with the forelegs and grasps small quantities of dung from the main pile (or sometimes from balls of other beetles) and adds them to the lump (fig. I). I do not know how the beetle estimates the quantity of dung in the lump. The process of cutting takes 2 - I 4 min, averaging $8.7 \mathrm{~min}$ ( I 2).

Shaping. Once cut and detached, the crude lump is converted into a more or less perfect sphere. Before shaping, the detached lump may be rolled a short distance $(3-30 \mathrm{~cm})$ away from the main pile. The process of shaping involves patting the lump rapidly over and over with the underside of the fore tibiae acting alternately, with the beetle climbing over the surface of the ball (fig. 2) or lying to one side of it and rotating the ball slowly so that the entire surface is patted many times over. The head may also be used to trim lumps or fibers off the ball surface during this process. Occasionally, new material may be added to the ball during the shaping process also (2). For the food ball, the shaping process takes $2-7 \mathrm{~min}$, averaging 4.2 $\min \left(\mathrm{I}_{5}\right)$.

At this point the ball is made, the entire process (cutting and shaping) having taken $\mathrm{I} 2-20 \mathrm{~min}$ and averaged I $5 . \mathrm{I} \min (\mathrm{I} 2)$. The food balls are often crude and not symmetrical, and measure 15-23

Explanation of Plate 7

(All figures drawn from photographs taken by the author)

Fig. 1. Lone beetle adding more material to food ball during cutting process. Fig. 2. Lone beetle shaping food ball. Forelegs are used to pat surface of ball. Fig. 3. Male and female pair cutting brood ball. Beetle at right is severing ball at base. Fig. 4. Male and female pair shaping brood ball. Both beetles are going over surface of ball with forelegs. Fig. 5. Rolling completed brood ball. Male is below, pushing ball backwards over an obstacle. Female is above, balancing on moving ball. This relationship of the sexes during rolling is invariable. Note smooth contours of completed brood ball. 
$\mathrm{mm}$ across their short diameter and $17-30 \mathrm{~mm}$ across their long, averaging $19.8 \times 22.9 \mathrm{~mm}$ (I I).

At one location (Brunswick, Ga.), I repeatedly noted a curious activity by eight of the 18 beetles observed. It occurred during the shaping process and involved rapidly rotating the ball in the sand, in a stationary position, for about two minutes with the result that the ball became coated with sand. As the ball acquires a sand coat on being rolled anyway, this observation cannot yet be explained.

Rolling. Once shaped, the ball is quickly rolled in a direction away from the dropping. Rolling is performed with the beetle headdownward behind the ball, pushing backward against the ground with the forelegs and steadying the ball with the middle and hind legs. The middle legs alternate between the ground and the ball and the hind legs are always in contact with the ball, alternately pushing against its surface with walking movements. When an obstacle is encountered the beetle will always attempt to push the ball over it rather than go around it (fig. 5). Frequent falls and tumbles occur, as a result of which the beetle may temporarily lose the ball. If this happens, the ball is searched for on foot in random patterns by the beetle, antennae outstretched. The procedure before resuming rolling after a tumble is always the same: the beetle climbs on top of the ball and turns so as to come down on the side of the ball necessary to resume rolling in the same direction in which it was rolling immediately before the tumble. Occasionally (2), the beetle will pause seemingly without reason, climb on the ball, turn around in either direction, and descend to resume rolling.

Once started in a given direction, the beetle will continue in this direction about half the time ( 13 of 23 ), although the actual course followed is quite zig-zag at best. The rest of the time there are pronounced changes in direction during rolling (enforced direction changes due to obstacles are not counted here). I have attempted to relate the direction in which a ball is first rolled away from the dropping to three possible environmental factors: the wind direction, the slope of the ground, and the position of the sun. In figures $6-$ Io I have indicated by dots the initial directions taken in relation to each of these three factors in turn, according to 70 observations on both food and brood balls in all localities. The number of dots indicates the number of times a ball was seen rolled at a given angle (to the nearest $45^{\circ}$ ) from the position or direction of the environmental factor indicated.

Chi-square calculations were made on each of the diagrams to 
ascertain the probability that the distributions obtained might have resulted by chance. Four class intervals were used for this, corresponding to four directions rather than the eight shown in the diagrams, since the numbers are too small to give meaningful results for eight class intervals. The chi-square figures and corresponding probabilities for three degrees of freedom are indicated in each diagram.

The diagrams and numbers may be interpreted as follows: If the distribution is significantly skewed when all observations are plotted in relation to the direction of one particular factor, we may expect that this factor overrides all others in governing the direction the ball is rolled. Such a factor is obviously the slope of the ground, the beetles rolling uphill $(\mathrm{P}=<.005)$ (fig. 8). Another strong factor appears to be the wind direction (balls rolled with the wind), but it is evidently not as overriding $(\mathrm{P}=.025-.05)$ (fig. 6). When all observations are plotted in relation to the position of the sun, the resulting diagram is not very strongly skewed, having a relatively high probability of being a chance distribution $(\mathrm{P}=.05-. \mathrm{IO})$ (fig. 9). We may interpret this to mean that the sun position is the least influential of the three factors analyzed.

In order to pinpoint more accurately the influence of a single factor it is better to subtract observations which were also under the influence of other factors. It was possible to plot the directions in relation to the wind where the ground was level (minus the ground slope factor) (fig. 7), but this did not reveal a more significant relationship, for some reason. To have subtracted the sun factor as well would have left too few observations.

The situation with regard to the sun is quite different when we plot the observations obtained when the other factors played no part, that is, when there was no wind and the ground was quite flat. In these cases, the distribution is very significantly skewed, with I 3 out of the 19 observations being either directly toward or directly away from the sun (fig. Io). The probability that this could have been brought about by chance is .005. It appears, therefore, that the sun is used in some way in guidance, providing more important factors do not intervene. More will be said on this matter in the discussion at the end of the paper.

The relation to the wind may be simply explained: the beetle approaches the dung from down-wind and therefore tends to work on the leeward side of the dropping. Once made, the ball is simply rolled away from the dropping, and this will automatically be more or less in the direction of the wind, other factors being equal. The 
Directions Rolled in Relation to Three Environmental wind Factors wind
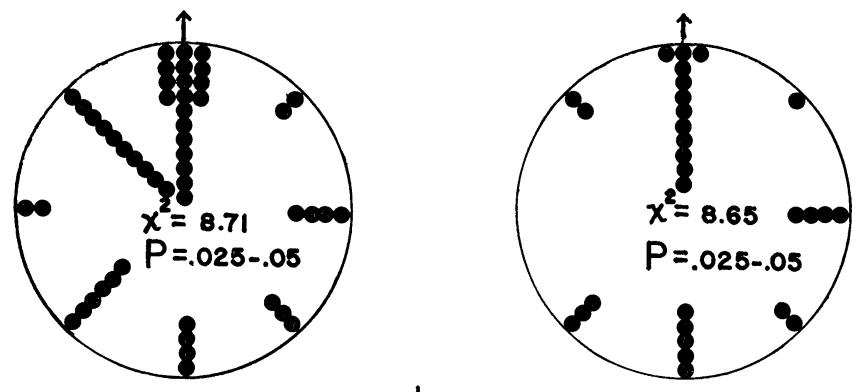

6. All observations

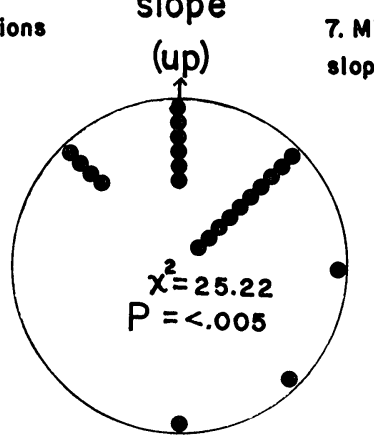

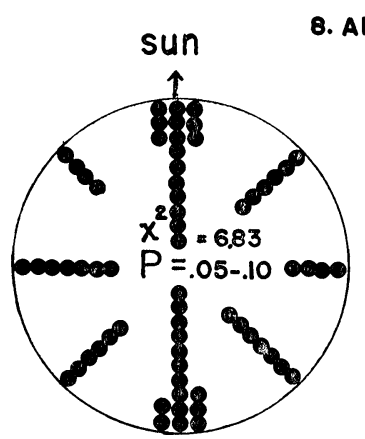

9. All observations

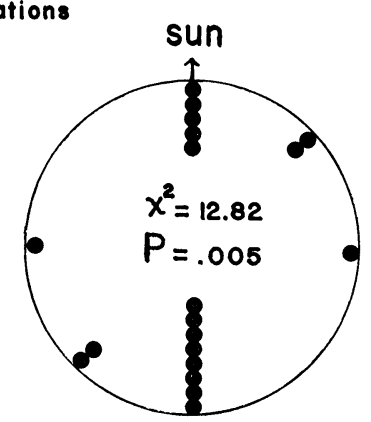

10. Minus ground slops and wind factors

MatThews - CANTHON 
tendency to uphill rolling may also be simply explained by the fact that it is difficult to roll a ball sideways or downward on a slope without losing control of it.

The length of time that a food ball is rolled before burial varies from two to $18 \mathrm{~min}$ and averages $9.5 \mathrm{~min}$ ( 16 ) (not "about an hour or more" as Lindquist states), and the distance rolled depends a great deal on terrain, of course; a heavily grassed or littered area impedes the progress of the beetle. The distance from the dropping that the food ball is rolled before burial varies from 15 to $830 \mathrm{~cm}$, averaging $267 \mathrm{~cm}$ (19). This is not the straight-line distance, but that actually travelled by the beetle, as measured by tracing a line on the ground behind the beetle and measuring each twist and turn.

It is evident that almost any spot will do for burial and the beetle is not "seeking" an ideal spot. It is not clear what factors prompt the beetle to begin burial, as both the time and distance rolled are very variable.

Burial. When the time for burial has arrived the beetle will pause and dig a little in the soil under the ball. This is presumably to test the ground to see if it is suitable for burial. Usually ( 12 of 16 ), the very first spot tested is that where the ball is buried. Otherwise ( 4 of 16 ), one or two other spots are tested before the final burial place is chosen, the beetle resuming rolling after rejecting a spot. Burial takes place by pushing soil to the sides from under the ball in such a manner that the beetle sinks rapidly into the ground with the ball on top of it. The food ball is buried $1.5-4 \mathrm{~cm}$ below the surface, that is to say, at a very shallow depth (9). At Brunswick, $\mathrm{Ga}$, where I measured soil temperatures at burial depth I found them to be only $\mathrm{I}-9^{\circ} \mathrm{C}$ below the air temperature of $35^{\circ} \mathrm{C}$ ( IO).

Feeding. What happened after the food ball was buried was not directly observed, but some idea of the underground activity could be gained by unearthing different balls and beetles at varying intervals after burial. Fourteen such balls were dug up at intervals of $\mathrm{I}: 35$ to 49:30 hrs after burial and indicated the following: The beetle may not begin to nibble at the ball up to $6: 08 \mathrm{hrs}$ after burial, but on the other hand it may have begun feeding at $\mathrm{I}: 35 \mathrm{hrs}$ or earlier. The

\section{Explanation of Plate 8}

Figs. 6-10 represent the directions in which balls were seen rolled in relation to three different environmental factors in all localities, to the nearest $45^{\circ}$ angle. Total of beetles observed is 70 . Each dot represents one observation in the given direction. Chi-square and corresponding probability figures for three degrees of freedom are given in each diagram. Further discussion in text. 
ball is entirely consumed in $26-30$ hrs after burial. The beetle stays with the remains of the ball for some hours and sometime between 30 and 50 hrs it departs, leaving only coarse fibers and beetle excrement in the hole.

Feeding by adults is said to occur also directly on the dropping, without a ball having been previously made (Lindquist, I935). I have not observed this in this species in the field, although this habit is common in a related species (C. chalcites [Haldeman]).

\section{The Brood Ball}

The behavior involved in the making and rolling of the ball destined to be converted into a brood pear ${ }^{3}$ and serve as food for the larva is similar to that just described for the adult food ball but differs in a number of respects, the most important of which is the participation of both sexes in the making of a single ball. Although the importance of the male's role in this respect had been foreshadowed by comments in the literature on other species and genera (cf., e.g. Halffter, I96I, on $C$. h. humectus [Say]), I was surprised at the extent of the male's participation. The male plays the leading role in the making of the brood ball, and it is he exclusively who rolls, defends, and buries the ball, the female's role in these activities being purely passive.

The following account will deal in turn with the encounter of the sexes, the making of the ball, rolling and burial, robbery and combat, and underground activity.

The encounter of the sexes. I was able to observe the crucial moment of the meeting of the future pair only twice, and both of these instances are described in detail below. They are probably rather unusual in the lateness of the encounter in the behavior sequence, since in both cases the female only joined the male ball maker after the latter had completed the ball. More usually ( I I of I3), the two members of the pair are seen cooperating in making the ball (figs. 3, 4). This means that the sexes meet and join early in the ball making process. From the two observed instances described below, it seems most probable that the male initiates the ball-making process and is subsequently joined by the female.

The first instance was observed near Brunswick, Ga., on 13 June, 1957. A large green male began making a ball (after trying to rob one from another male) at i235. At I3 IO he was still shaping the ball with very great care. At I3 I a small black female landed nearby and approached. She was met with hostility and repeatedly rebuffed

\footnotetext{
${ }^{3}$ The term "brood pear" is a rendering of the German "Brutbirne" and is much more descriptive than the usual term "egg ball".
} 
by the male, who used fighting movements to be described in the section on combat, but she persisted until the male accepted her presence. She climbed onto the ball and, since it was completed, it was rolled off at 1312 by the male, with the female clinging to it. The activities of this pair were followed for nine days in captivity and resulted in the formation of a brood pear containing an egg.

The other instance was observed near Welaka, Fla., on 6 May, 196r. A male was first seen making a ball with very great care and was observed for 20 minutes painstakingly patting the ball to a smooth sphere. During this time the beetle had to repulse no less than seven male intruders (the sex was checked in each case) apparently bent on robbing the ball. One intruder was chased some distance. The eighth intruder appeared when the ball was completed and about to be rolled off and was met with equal hostility, being rebuffed several times. It kept coming back, however, and was finally accepted, climbing onto the ball and being rolled off with it. On subsequent examination it proved to be a female.

These two observed instances of the moment of encounter are very much alike in that in both cases the male had completed the ball before he was joined by the female, and the male rebuffed the female several times before accepting her. Perhaps when the encounter occurs earlier, as it normally does, the male is less hostile.

The making of the ball. It will be noted from the first account above that the cutting and shaping of the brood ball by the male took 35 min, whereas cutting and shaping the food ball takes a maximum of 20 min. I also came across seven more pairs at work on the brood ball and watched them work for more than 20 additional minutes in all cases. It is evident, therefore, that a great deal more care is taken in making the brood ball, particularly in the shaping process. The interesting point is that a male beetle makes a brood ball even when he is all by himself, before being joined by the female. This is shown by the length of time spent in shaping the ball, and the experienced observer can always tell quite readily whether a food ball or a brood ball is being made by a lone beetle. I have seen ten males making brood balls alone, but no females. It seems most probable, therefore, that the male initiates the brood ball making process and is then joined by the female, who cooperates in both the cutting (fig. 3 ) and shaping (fig. 4) processes.

As may be imagined from the great deal of shaping that the brood ball undergoes, it is a much more perfect sphere than the food ball 
and has a much smoother surface (fig. 5), but there is no reason to believe that it contains any material different or more selected than the adult food ball. All the extra care appears to go into the surface layer. The brood ball measures $20-22 \mathrm{~mm}$ in diameter (IO).

Rolling and burial. Unlike the food ball, which once shaped is rolled off more or less without interruption, the brood ball is often shaped several times during pauses in the rolling process. Shaping, as previously stated, is a cooperative act of the sexes and the female will often be seen continuing shaping even while the ball is being rolled. It is the male exclusively who rolls ( 17 ), the female merely walking head upward over the forward surface of the ball in time with its rotation, as on a tread mill (fig. 5). She does not help in the rolling process in any way that I could see, except perhaps as a counterweight. On the contrary, when the male has temporarily lost the ball after a tumble or is fighting off an attacker, the female will sometimes make off with the ball herself (3). In the three such cases observed the male soon caught up with the female rolling the ball and displaced her in the rolling position, whereupon the female climbed back onto the ball.

Table I. Data on dung balls made by Canthon pilularius (L.)

\begin{tabular}{|c|c|c|c|c|c|c|}
\hline \multirow{3}{*}{$\begin{array}{l}\text { Time for } \\
\text { making ball }(\mathrm{min})\end{array}$} & \multicolumn{3}{|c|}{ FOOD BALLS } & \multicolumn{3}{|c|}{ BROOD BALLS } \\
\hline & Range & Average & $\mathbf{N}$ & Range & Average & $\mathbf{N}$ \\
\hline & $12-20$ & 15.1 & 12 & $>20-35$ & - & 8 \\
\hline Size of ball (mm) & $15-23 \times 17-30$ & $19.8 \times 22.9$ & 11 & $20-22 \times 20-22$ & $20.7 \times 20.7$ & 10 \\
\hline Time rolled $(\min )$ & $2-18$ & 9.5 & 16 & $3-23$ & 9.3 & 10 \\
\hline $\begin{array}{l}\text { Distance rolled } \\
(\mathrm{cm})\end{array}$ & $15-830$ & 267 & 19 & $90-1060$ & 414 & 14 \\
\hline Depth buried $(\mathrm{cm})$ & $1.5-4$ & 2.6 & 9 & $6-10$ & 7.6 & 9 \\
\hline
\end{tabular}

The actual rolling process is the same as that described for the food ball. During the orientation pauses after a tumble, when the male roller climbs onto the ball, he comes into contact with the female but no longer displays any hostility toward her.

The distances that brood balls are rolled vary from 90 to $\mathrm{I}, 06 \mathrm{om}$, averaging $4 \mathrm{I} 4 \mathrm{~cm}$ ( 14 ), and are thus somewhat more than the distances recorded for the food balls, although the time spent rolling seems to average the same (table I).

The burying process is the same as that described for the food ball. The male does all the work, the female clinging passively to 
the ball and being buried with it. As the ball begins to disappear below the surface the female will dig down beneath it, presumably to ensure that she will not be left at the surface. The brood ball is buried 6- I0 $\mathrm{cm}$ below the surface (9), two or three times as deep as the food ball. Subsequent activity underground is discussed below.

Since the encounter of the sexes is a chance one, there are many instances when the male, having completed a brood ball, is not joined by any female. In this case, he will roll the ball off anyway and bury it (8). One such ball was dug up I 8 hrs later and was found intact, with the male next to it. This suggests that the beetle stays with the ball for a time without eating it, and then perhaps abandons it. Abandoned brood balls are not rare in a pasture.

Robbery and combat. Few attempts at ball robbery are observed during feeding activity later in the season, but during mating activity in the spring such attempts are extremely frequent and ball makers are under constant attack. In all instances checked (2I), the attackers were males and the defenders also males. Since the female apparently never initiates ball making on her own, but joins a male already busy, she does not have to defend any balls and is not involved in combat. When the mating pairs have joined, the male of the pair is always the one called upon to repel attackers, the female usually sitting on the ball during the fight. In only one instance was I able to observe a successful robbery, the usurper making off with both the ball and the female of the other male.

The fighting movements involve primarily the head, which is used to butt, that is to say, to push upward and outward against the opponent. Each antagonist attempts to place the edge of its head under some part of the body of the opponent and then quickly jerk it upward. If successful, this procedure flips the opponent away and onto its back. The defender of a ball always has the advantage because it can use the ball to protect its underside by clinging closely to it, hence the small number of successful robberies. In addition to the head, all the legs are often used and the beetles may grapple together. Fights are of very brief duration and apparently do not result in any injury to the participants.

To summarize, the typical situation at a cow dropping during the reproductive season is as follows. A few males and pairs are making balls and several males are roving about trying to steal a ball rather than make one. These males are repulsed by the males of the pairs 
making balls, or the single male ball makers. One or two females may also be wandering around, presumably looking for mates. When one of these females comes upon a lone ball maker, she will probably be accepted, as we have seen. When she approaches a pair, the male of the pair will repel her (2). Ball rollers are also frequently attacked by roving males and violent fights may ensue.

Underground activity. When the soil is sufficiently compact to allow it, the ball and pair are in a definite chamber which is just large enough to hold the ball and the beetles. There is about 5- 10 $\mathrm{mm}$ of space all around the ball. A definite passageway, which is left open, leads down at an angle from the surface. The nest is marked at the surface by a very low mound of loose soil, often very difficult to detect except to the experienced eye. As previously stated, the ball is buried 6 - Io $\mathrm{mm}$ below the surface.

What occurs underground was investigated by digging up seven brood balls whose burial had been observed, at varying intervals after burial. In addition, I 7 older brood pears were dug up in various pastures in Florida in April. Copulation apparently takes place a few hours after burial. Only one instance of this was observed; this was near Arcadia, Fla., on 27 March, 1957, 3:10 hrs after burial. The pair were unearthed in coitu next to the ball. On four other occasions the male was still present in the nest up to $2 \mathrm{I}: 35 \mathrm{hrs}$ after burial. On the other two occasions investigated, $2 \mathrm{I}$ and $22 \mathrm{hrs}$ after burial, the male was gone, the female being alone with the as yet unmodified brood ball. It seems therefore that the male's role, far more important than is usual among insects, is terminated at about this point. On all these occasions the brood ball had not been touched and was still spherical. Some time after the male departs the female must lay one egg into the ball and convert it into a pear. I have not observed this process and do not know when or how it occurs. In captivity, a ball made by a male in the manner described for brood balls, and rolled and buried with the female, was converted into a pear containing an egg in a period between four and ten days after it was buried.

Once converted into a pear, the ball is abandoned by the female and left unattended in the soil. I collected I 7 such unattended brood pears in several pastures at Welaka, Fla., in April, 196r. Those broken open were found to contain either a first-, second-, or thirdinstar larva. The brood pear and larva have been described elsewhere (Lindquist, 1935; Ritcher, 1945). Lindquist gives the development intervals for each instar and gives the total development 
period from hatching to adulthood as $29-44$ days in captivity. There is only one brood pear per nest.

\section{Discussion of Sun Orientation}

The observations presented above on the possible role of the position of the sun in guiding the direction of ball rolling merit some discussion in view of the considerable amount of experimental work done in Europe over the past ten years on this aspect of behavior in a geotrupine scarab, Geotrupes sylvaticus Panz. (see especially Geisler, I 96 I).

My observations above suggest that in the absence of stronger guiding stimuli Canthon tends to roll away from the dropping in a direction which is either directly toward or directly away from the position of the sun (i.e., at an angle of $\mathrm{O}^{\circ}$ or $\mathrm{I}^{\circ} \mathrm{0}^{\circ}$ ) (fig. IO). By extensive experimentation Geisler (I96I) was able to demonstrate definite "preference angles" (Vorzugswinkel) of travel in Geotrupes of $90^{\circ}, 45^{\circ}$, and $0^{\circ}$ angles from the position of the sun or the plane of oscillation of polarized light from the sky. Whether the preference angles are to the right or to the left of the sun depends on whether it is afternoon or before noon respectively. This is brought about by the use of the right eye in the morning and the left eye in the afternoon for orientation and makes east the preferred direction in the morning and west in the afternoon. The alternation of eye use and consequent complete reversal of preferred direction (bearing in mind the movement of the sun) enables the beetle to return in the afternoon to the place it left in the morning. Geotrupes, therefore, has a definite compass-true orienting ability - requiring an angletrue orientation plus a time sense ("built-in clock").

According to Wagner (I957), the sun plays an important part in orientation during ball rolling also, the beetles apparently using its position to maintain travel in a given direction, the most frequent direction being directly toward the sun. These observations were carried out in Mexico on "Geotrupinae" - however, this subfamily does not roll balls and it seems almost certain that a species of Canthon was involved.

The Geotrupinae are neither ball rollers nor primarily dung beetles, but it is possible that the light-compass orientation seen in $G$. sylvaticus occurs also in Canthon and other ball rollers. The exact adaptive purpose of this orienting ability is not clear either in Geotrupes or Canthon, but it will be remembered that after a tumble $C$. pilularius always climbs on top of the ball before resuming rolling. 
This may possibly be to orient to the sun in order to continue rolling in the same direction as before.

\section{Summary}

The natural behavior in the field of the common Eastern tumblebug Canthon pilularius (L.) is discussed. Two types of dung balls are made: food balls and brood balls. The former are made, rolled, and buried by a single beetle of either sex to serve as food for itself, the latter are made, rolled, and buried by a male, accompanied by a female, to serve as food for a single larva.

Both types of balls are made, rolled, and buried similarly and involve a succession of separate processes. Time intervals and measurements are given for each phase of the behavior sequence. The brood ball is shaped much more carefully than the food ball and is a more perfect sphere; it is rolled farther and buried deeper.

The direction in which a ball is rolled away from the dropping was found to have some relationship to the slope of the ground, the wind direction, and the position of the sun, in that order of priority. Some discussion of sun orientation is presented.

The male is always the active partner in relation to the brood ball - he initiates ball making before the female joins him, he rolls the ball entirely, defends it from other males, and buries it unaided. The female cooperates only in making the ball and is otherwise passive.

The pair copulate soon after burial and the male seems to stay about 22 hours with the ball and female. The female stays several days longer to lay one egg in the ball and convert it into a brood pear, which is then abandoned and left unattended in the soil.

\section{References Cited}

BragG, A. N.

1957. Use of carrion by the beetle, Canthon laevis (Coleoptera, Scarabaeidae). Southwest. Nat., $2(4): 173$.

COOPER, R. H.

1938. Tumble-bugs. Canadian Ent., 70:155- 157.

GeisLer, M.

1961. Untersuchungen zur Tagesperiodik des Mistkäfers Geotrupes silvaticus Panz. Zeits. Tierpsych. $18(4): 389-420$.

HALFFTER, G.

1959. Etología y paleontología de Scarabaeinae (Coleoptera, Scarabaeidae). Ciencia (Méx.), 19:165-178.

1961. Monografía de las especies norteamericanas del género Canthon Hoffsg. (Coleoptera, Scarabaeidae). Cinecia (Méx.), 20:225320.

HARDE NBerg, C. B.

1907. Comparative studies in the trophi of Scarabaeidae. Trans. Wisconsin Acad. Sci., 15:548 - 602 . 
LANDin, B.-O.

1961. Ecological studies on dung-beetles. Opusc. Ent. Suppl., 19:1228.

LANE, F.

1950. Sobre os tipos e a sinonimia de alguns Canthonini (Col., Scarabaeidae). III. Nota sobre a data certa de Canthon laevis Drury. Pap. Av. Depto. Zool. (S. Paulo), 9(7):79-81.

LENGERKEN, H. vON

1954. Die Brutfürsorge und Brutpflegeinstinkte der Käfer. Leipzig, Akad. Verlags., 383 pp, 241 figs.

LINDQuist, A. W.

1935. Notes on the habits of certain coprophagous beetles and methods of rearing them. Circ. United States Dept. Agr. 351, 9 pp, 2 figs.

LUEDERWALDT, G.

1911. Os insectos necrophagos paulistas. Rev. Mus Paulista, 8:414433.

Miller, A.

1954. Dung beetles (Coleoptera, Scarabaeidae) and other insects in relation to human faeces in a hookworm area of southern Georgia. American Jour. Trop. Med. Hyg., 3 (2) : $372-388$.

1961. The mouthparts and digestive tract of adult dung beetles (Coleoptera, Scarabaeidae) with reference to the ingestion of helminth Mohr, C. O. eggs. Jour. Parasitol., $47(5): 735-744$.

1930. Morphological comparisons of Coprinae, Aphodiinae, and Geotrupinae. Trans. Illinois St. Acad. Sci., 22:263-284.

Pereira, F. S. and A. Martínez.

1956. Os gêneros de Canthonini americanos. Rev. Brasileira Ent., 6: $91-192$.

Ritcher, P. O.

1945. Coprinae of Eastern North America with descriptions of larvae and keys to genera and species (Coleoptera, Scarabaeidae). Bul. Kentucky Agr. Exp. Sta. 477, 23 pp., 3 pls.

WAGNER, H. O.

1957. The biological function of the menotactic light orientation in dung beetles. Freiburg i. Br., Vierte internationale Ethologenkonferenz, Sept. 1957, Abrisse und Summaries. Mimeogr., no pag. 

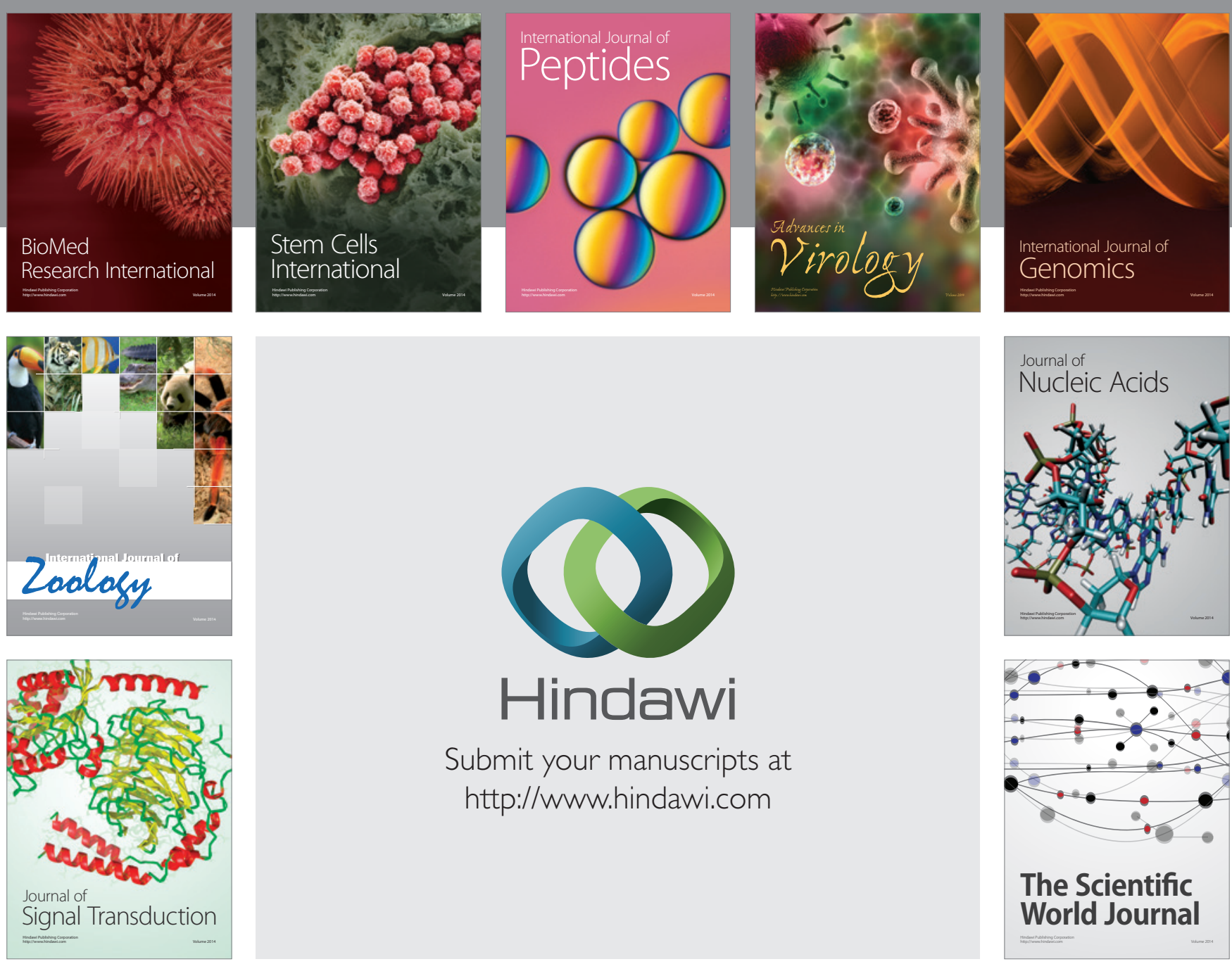

Submit your manuscripts at

http://www.hindawi.com
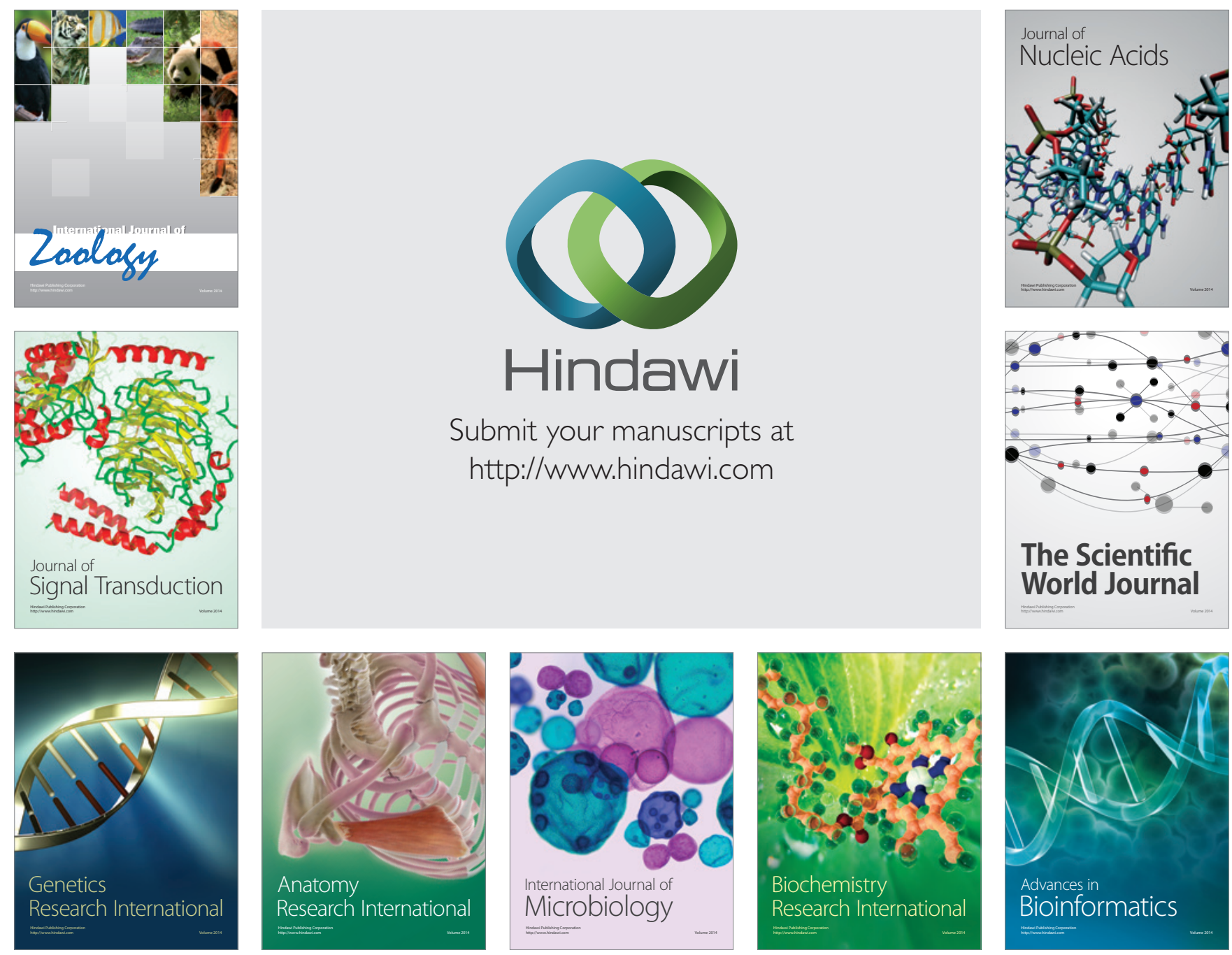

The Scientific World Journal
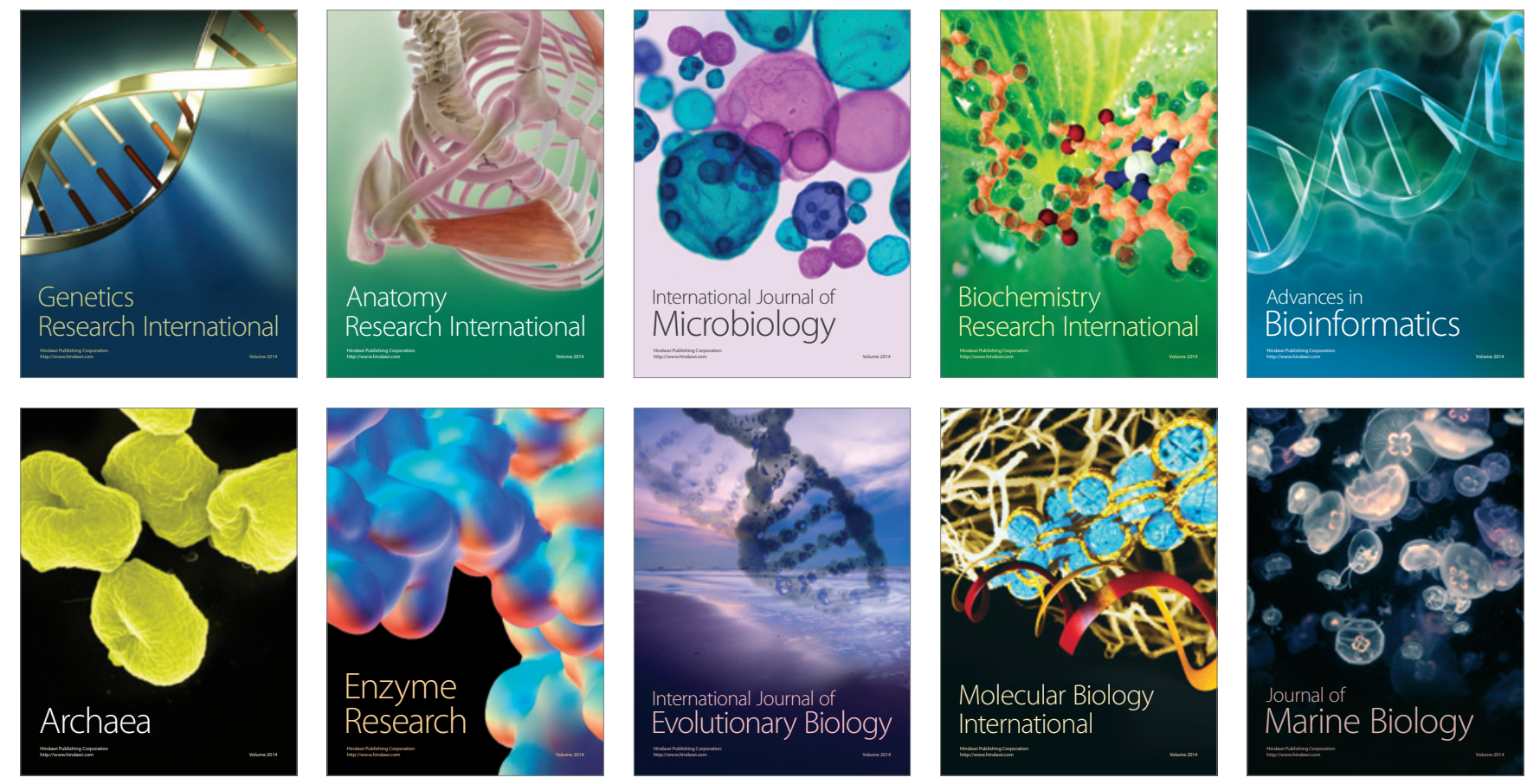